\title{
Mass Spectra of Some Deuteroethanes
}

\author{
Edith I. Quinn ${ }^{1}$ and Fred L. Mohler ${ }^{2}$
}

(November 11, 1960)

\begin{abstract}
Mass spectra of seven of the nine possible deuteroethanes have been measured. When the patterns are computed on a scale to make the sums of ions equal, it is found that the abundances of molecule ions differ nearly twofold in the different molecules, and there are large differences in the patterns of the two $\mathrm{C}_{2} \mathrm{H}_{4} \mathrm{D}_{2}$ molecules. The peaks in the $\mathrm{C}_{1}$ range are compared with the patterns predicted for simple breaking of the $\mathrm{C}-\mathrm{C}$ bond and dissociation of the methyl radicals. The "weighting factors" for removing $\mathrm{H}$ and $\mathrm{D}, \mathrm{HD}$, and 2D, etc., from $\mathrm{C}_{2} \mathrm{HD}_{5}$ are computed and also the weighting factors for $\mathrm{H}^{+}$and $\mathrm{D}^{+}$for all the deuteroethanes are given.
\end{abstract}

\section{Introduction}

While there is a rather extensive literature on mass spectra of deuterohydrocarbons, published data on deuteroethanes are fragmentary. Schissler, Thompson, and Turkevich $[1]^{3}$ published mass spectra of four deuteroethanes in 1951 in the mass range 12 to 36 and Dibeler [2] published a mass spectrum of $\mathrm{C}_{2} \mathrm{D}_{6}$ of good purity.

We were able to obtain samples of seven of the nine possible deuteroethanes. Two of these were synthesized by M. deHemptinne of the University of Louvain and the others were purchased from Merck Inc. Mass spectra were recorded with a $180^{\circ}$ Consolidated model 21-103 mass spectrometer following standard operating procedures. The ionizing voltage is $70 \mathrm{v}$ except as noted below.

\section{Results}

The samples were all of good chemical purity and an isotopic analysis was made by recording the spectrum at an ionizing voltage low enough to give molecule ions but not fragment ions [3]. Table 1 lists the seven deuteroethanes, the isotopic analysis and the source of the samples. This is a difficult analysis for ethane as the appearance potentials of the fragment ions are close to the ionization potential of the molecule. Field and Franklin [4] give appearance potentials as follows : $\mathrm{C}_{2} \mathrm{H}_{6}^{+}, 11.6 \mathrm{ev}, \mathrm{C}_{2} \mathrm{H}_{5}^{+}$, $12.8 \mathrm{ev}$; and $\mathrm{C}_{2} \mathrm{H}_{4}^{+}, 12.1 \mathrm{ev}$. This makes the measurement insensitive. (The impurity with one less $\mathrm{D}$ atom than the sample may be uncertain by 10 percent of the stated amount.) The mole percent impurities listed are consistent with the purity reported by Merck in round numbers as 98 and 99 atom percent.

\footnotetext{
${ }^{1}$ Mrs. Lile F. Davis, State College of Technology, Beaumont, Texas.

2 Consultant, National Bureau of Standards.

3 Figures in brackets indicate the literature references at the end of this paper.
}

TABLE 1. Mole percent impurities in deuteroethanes

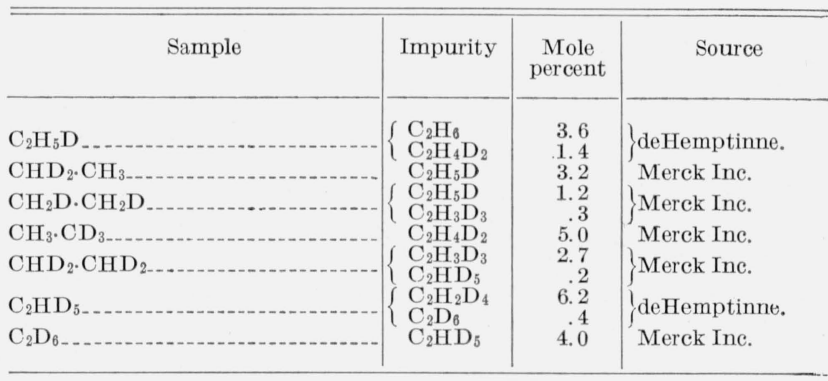

Table 2 gives the mass spectra of $\mathrm{C}_{2} \mathrm{H}_{6}$ and the seven deuteroethanes. The contributions of ions containing $\mathrm{C}^{13}$ and of isotopic impurities from table 1 have been subtracted from the spectra. The patterns of the different molecules have been normalized in an unconventional manner. It seemed logical to present the spectra on a scale to make the parent ion abundances all equal but when this is done it is found that there is a wide variation in the sums of all the ions in the spectrum. It seems unlikely that there is a wide variation in the total ionization of molecules that differ only in the isotopic masses of the atoms although difference of mass distribution will change the pattern of dissociation. In table 2 the patterns are on a scale to make the sums of the ions equal to the sum for $\mathrm{C}_{2} \mathrm{H}_{6}$ with the conventional scale of abundances used for the $\mathrm{C}_{2} \mathrm{H}_{6}$ pattern.

It is evident that on this scale there is a wide variation of the abundances of the molecule ions. It ranges from 13.0 for $\mathrm{CH}_{3} \cdot \mathrm{CD}_{3}$ to 23.0 for $\mathrm{C}_{2} \mathrm{H}_{5} \mathrm{D}$. Both of the highly unsymmetrical molecules $\mathrm{CH}_{3} \cdot \mathrm{CD}_{3}$ and $\mathrm{CH}_{3} \cdot \mathrm{CHD}_{2}$ give low values of the molecule ion. There are many other conspicuous differences between the mass spectra of the symmetrical and unsymmetrical molecules of $\mathrm{C}_{2} \mathrm{H}_{4} \mathrm{D}_{2}$ in columns 4 and 5 . 
TABLE 2. Mass spectra of deuteroethanes on a scale to make the sums of ions equal

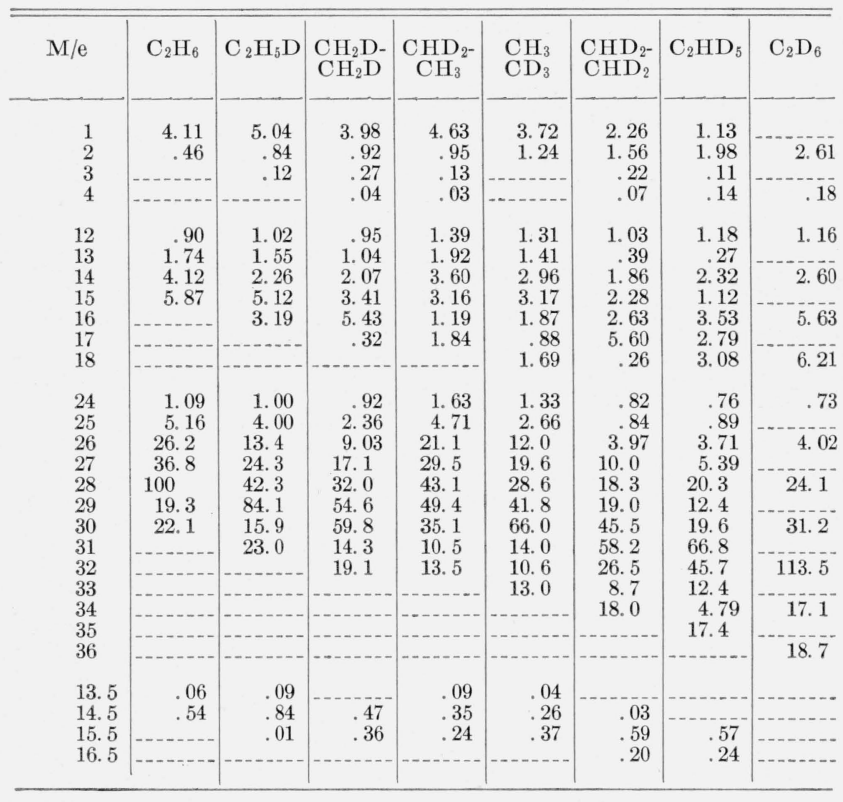

As a general rule the removal of $D$ atoms from deuterohydrocarbons is less probable than the removal of $\mathrm{H}$ but $\mathrm{C}_{2} \mathrm{D}_{6}$ affords a notable exception. The $\mathrm{C}_{2} \mathrm{D}_{4}{ }^{+}$ion has an abundance of 113.5 as compared with 100 for $\mathrm{C}_{2} \mathrm{H}_{4}{ }^{+}$of $\mathrm{C}_{2} \mathrm{H}_{6}$. In the patterns of ethanes containing $\mathrm{H}$ and $\mathrm{D}$ two different ions contribute to many of the peaks. Thus $\mathrm{C}_{2} \mathrm{H}_{2}{ }^{+}$and $\mathrm{C}_{2} \mathrm{D}^{+}$ contribute to mass $26, \mathrm{C}_{2} \mathrm{H}_{3}{ }^{+}$and $\mathrm{C}_{2} \mathrm{HD}^{+}$to 27 etc. In the deuteroethane spectra there is no safe basis for computing the relative probability of removing $H$ and $\mathrm{D}$ or several $\mathrm{H}$ and $\mathrm{D}$ atoms except in the $\mathrm{C}_{2} \mathrm{HD}_{5}$ spectrum. In that spectrum each peak comes from a single isotopic fragment ion.

Table 3 gives in the third column the pattern of $\mathrm{C}_{2} \mathrm{HD}_{5}$ with the peaks grouped in pairs of ions containing 1, 2, 3, etc., hydrogenic atoms. The sums of these pairs in column 4 give the relative proba-

TABLE 3. Pattern of $\mathrm{C}_{2} \mathrm{HD}_{5}$ and theretical pattern in $\mathrm{C}_{2}$ range

\begin{tabular}{|c|c|c|c|c|c|c|c|}
\hline $\mathrm{M} / \mathrm{e}$ & Ions & Pattern & $\begin{array}{c}\text { Sums of a } \\
\text { pairs }\end{array}$ & $\begin{array}{l}\text { a'priori } \\
\text { proba- } \\
\text { bility }\end{array}$ & $\begin{array}{c}\text { Theoret- } \\
\text { ical b }\end{array}$ & $\begin{array}{l}\text { Weight }{ }^{\mathrm{e}} \\
\text { factor }\end{array}$ & $\begin{array}{c}\mathrm{C}_{2} \mathrm{D}_{6} \\
\text { pattern }\end{array}$ \\
\hline & $\mathrm{C}_{2}$ & 0.76 & $(0.76)$ & \multirow{9}{*}{$\begin{array}{c}1 \\
1 / 6 \\
56 \\
1 / 3 \\
2 / 3 \\
1 / 2 \\
12 \\
2 / 3 \\
1 / 3 \\
56 \\
1 / 6 \\
1\end{array}$} & \multirow{9}{*}{$\begin{array}{c}0.76 \\
.77 \\
3.83 \\
8.57 \\
7.13 \\
16.0 \\
16.0 \\
75 . \\
37.5 \\
14.3 \\
2.87 \\
17.4\end{array}$} & \multirow{3}{*}{$\begin{array}{r}1.15 \\
.97 \\
.63\end{array}$} & \multirow[t]{2}{*}{0.73} \\
\hline $\begin{array}{l}25 \\
26\end{array}$ & $\begin{array}{l}\mathrm{C}_{2} \mathrm{H} \\
\mathrm{C}_{2} \mathrm{D}\end{array}$ & $\begin{array}{r}.89 \\
3.71\end{array}$ & 4. 60 & & & & \\
\hline 27 & $\mathrm{C}_{2} \mathrm{HD}$ & 5. 39 & & & & & 4.02 \\
\hline 28 & $\mathrm{C}_{2} \mathrm{D}_{2}$ & 20.3 & 25.7 & & & \multirow{2}{*}{$\begin{array}{l}1.18 \\
.78\end{array}$} & 24.1 \\
\hline $\begin{array}{l}29 \\
30\end{array}$ & $\begin{array}{l}\mathrm{C}_{2} \mathrm{CD}_{2} \mathrm{H}_{3} \\
\end{array}$ & $\begin{array}{l}12.4 \\
19.6\end{array}$ & 32.0 & & & & 31.2 \\
\hline 31 & $\mathrm{C}_{2} \mathrm{HD}_{3}$ & 66.8 & & & & $\begin{array}{r}1.22 \\
.89\end{array}$ & \\
\hline 32 & $\mathrm{C}_{2} \mathrm{D}_{4}$ & 45. 7 & 112.5 & & & \multirow{3}{*}{$\begin{array}{r}1.22 \\
.86 \\
1.67 \\
1.00 \\
\mathrm{C}_{2} \mathrm{D}_{6}\end{array}$} & 113.5 \\
\hline $\begin{array}{l}30 \\
34\end{array}$ & $\mathrm{C}_{2} \mathrm{D}_{5}$ & 4. 79 & 17 & & & & 17.1 \\
\hline & $\mathrm{C}_{2} \mathrm{H}$ & 17.4 & $(17.4)$ & & & & \\
\hline & & & & & & & \\
\hline
\end{tabular}

a The sums of the indicated pairs give the relative abundance of ions with 1 to 5 hydrogenic atoms.

b This column gives the a' priori probability, times the abundances of column 4. - This gives the ratio of the observed pattern and the theoretical pattern. bility of removing one to five atoms. This times the a'priori probability gives, in column 6 , the pattern predicted if removal of $\mathrm{H}$ and $\mathrm{D}$ were random. The experimental values divided by the theoretical give the "weighting factors" for removing $\mathrm{H}$ and D atoms and all possible combinations of these. It is seen that except for the 25, 26 pair, ions involving loss of the $\mathrm{H}$ atom have a weight factor greater than one and the otners less than one. This is qualitatively consistent with experiments with other deuterohydrocarbons. The weighting factors for removing $\mathrm{H}$ and D, 1.67 and 0.86 are of the magnitudes found for $\mathrm{CHD}_{3}$ [5] and $\mathrm{C}_{2} \mathrm{HD}_{3}$ [6]. There is, however, no regular trend in weighting factors for removing 1,2 , 3 , etc., atoms from $\mathrm{C}_{2} \mathrm{HD}_{5}$ such as was found in the deuteroethylene spectra [6].

In the last column of table 3 the observed pattern of $\mathrm{C}_{2} \mathrm{D}_{6}$ is given and it is quite similar to the "sums of pairs" of $\mathrm{C}_{2} \mathrm{HD}_{5}$ in column 4 . It is not surprising" that $\mathrm{C}_{2} \mathrm{HD}_{5}$ is more like $\mathrm{C}_{2} \mathrm{D}_{6}$ than $\mathrm{C}_{2} \mathrm{H}_{6}$.

The ions in the mass 12 to 18 range (table 2 ) involve breaking the $\mathrm{C}-\mathrm{C}$ bond and if this bond breaks without rearrangement of $\mathrm{H}$ and $\mathrm{D}$ atoms there will be a simple relation between patterns of unsymmetrical molecules and patterns of two symmetrical molecules. Thus the $\mathrm{CH}_{3} \cdot \mathrm{CD}_{3}$ fragment ions in the $\mathrm{C}_{1}$ range will involve contributions from $\mathrm{CH}_{3}$ and from $\mathrm{CD}_{3}$ as given by the $\mathrm{C}_{2} \mathrm{H}_{6}$ and $\mathrm{C}_{2} \mathrm{D}_{6}$ patterns. However the observed pattern shows a small 17 peak from $\mathrm{CHD}_{2}{ }^{+}$so there is some rearrangement.

'Table 4 compares the observed patterns for unsymmetrical molecules in the $C_{1}$ range and the patterns computed from the spectra of two symmetrical molecules. The last two rows give the basis of computation. Thus the $\mathrm{CH}_{3} \cdot \mathrm{CH}_{2} \mathrm{D}$ pattern is compared with 0.59 times the patterns of $\mathrm{CH}_{2} \mathrm{D} \cdot \mathrm{CH}_{2} \mathrm{D}$ plus 0.53 times the pattern of $\mathrm{C}_{2} \mathrm{H}_{6}$. In some cases as in the $\mathrm{CHD}_{2} \cdot \mathrm{CD}_{3}$ spectrum there is fairly good agreement between the observed and computed spectra while in $\mathrm{CH}_{3} \cdot \mathrm{CHD}_{2}$ the agreement is poor. In the $\mathrm{CH}_{3} \cdot \mathrm{CD}_{3}$ pattern there is a peak at 17 that comes from the rearrangement giving $\mathrm{CHD}_{2}{ }^{+}$and $\mathrm{CH}_{2} \mathrm{D}$ and the residual on the 16 peak comes from the same rearrangement with the charge on $\mathrm{CH}_{2} \mathrm{D}$.

TABLE 4. Mass spectra in the $\mathrm{C}_{1}$ range and computed values a

\begin{tabular}{|c|c|c|c|c|c|c|c|c|}
\hline \multirow{2}{*}{$\mathrm{M} / \mathrm{e}$} & \multicolumn{2}{|c|}{$\mathrm{C}_{2} \mathrm{H}_{5} \mathrm{D}$} & \multicolumn{2}{|c|}{$\mathrm{CH}_{3} \cdot \mathrm{CHD}_{2}$} & \multicolumn{2}{|c|}{$\mathrm{CH}_{3} \cdot \mathrm{CD}_{3}$} & \multicolumn{2}{|c|}{$\mathrm{C}_{2} \mathrm{HD}_{2} \cdot \mathrm{CD}_{3}$} \\
\hline & exp. & comp. & exp. & comp. & exp. & comp. & exp. & comp. \\
\hline $\begin{array}{l}12 \\
13 \\
14 \\
15 \\
16 \\
17 \\
18\end{array}$ & $\begin{array}{l}\text { 1. } 02 \\
\text { 1. } 55 \\
2.26 \\
\text { 5. } 12 \\
\text { 3. } 19\end{array}$ & $\begin{array}{l}1.04 \\
1.54 \\
3.41 \\
5.12 \\
3.19 \\
(.19)\end{array}$ & $\begin{array}{l}\text { 1. } 39 \\
\text { 1. } 92 \\
\text { 3. } 60 \\
3.16 \\
\text { 1. } 19 \\
\text { 1. } 84\end{array}$ & $\begin{array}{r}0.71 \\
.85 \\
2.31 \\
3.16 \\
.87 \\
1.84 \\
(.09)\end{array}$ & $\begin{array}{r}1.31 \\
1.41 \\
2.96 \\
3.17 \\
1.87 \\
.88 \\
1.69\end{array}$ & $\begin{array}{c}0.81 \\
.94 \\
2.94 \\
3.17 \\
1.53 \\
1.69\end{array}$ & $\begin{array}{r}1.18 \\
.27 \\
2.32 \\
1.12 \\
3.53 \\
2.79 \\
3.08\end{array}$ & $\begin{array}{r}1.06 \\
.19 \\
2.16 \\
1.13 \\
3.99 \\
2.79 \\
3.08\end{array}$ \\
\hline $\begin{array}{l}\text { Comp. } \\
\text { from }\end{array}$ & $.59 \times$ & $\begin{array}{l}\mathrm{H}_{2} \mathrm{D} \\
\mathrm{H}_{3}\end{array}$ & $\begin{array}{r}.33 \times \\
.41\end{array}$ & $\begin{array}{l}\mathrm{ID}_{2} \\
\mathrm{H}_{3}\end{array}$ & & $\begin{array}{l}\mathrm{KD}_{3} \\
\mathrm{C} \mathrm{CH}_{3}\end{array}$ & & $\mathrm{CD}_{3}$ \\
\hline
\end{tabular}

a Mass spectra of unsymmetrical molecules are computed from symmetrical molecules on the assumption that these ions come from breaking of the $\mathrm{C}-\mathrm{C}$ bond without rearrangement of $\mathrm{H}$ atoms. 
TABLE 5. Hydrogenic ions

\begin{tabular}{|c|c|c|c|c|c|c|c|c|}
\hline & $\mathrm{C}_{2} \mathrm{H}_{6}$ & $\mathrm{C}_{2} \mathrm{H}_{5} \mathrm{D}$ & $\begin{array}{l}\mathrm{CH}_{2} \mathrm{D} \\
\mathrm{CH}_{2} \mathrm{D}\end{array}$ & $\underset{\mathrm{CH}_{3}}{\mathrm{CHD}_{2}}$ & $\begin{array}{l}\mathrm{CH}_{3}^{-} \\
\mathrm{CD}_{3}\end{array}$ & $\begin{array}{l}\mathrm{CHD}_{2}^{-} \\
\mathrm{CHD}_{2}\end{array}$ & $\mathrm{C}_{2} \mathrm{HD}_{5}$ & $\mathrm{C}_{2} \mathrm{D}_{6}$ \\
\hline $\begin{array}{l}\mathrm{H}^{+} \\
\mathrm{D}^{+}\end{array}$ & 4. 11 & $\begin{array}{r}5.04 \\
.60\end{array}$ & $\begin{array}{r}3.98 \\
.72\end{array}$ & $\begin{array}{r}4.63 \\
.85\end{array}$ & $\begin{array}{l}\text { 3. } 72 \\
\text { 1. } 24\end{array}$ & $\begin{array}{l}2.26 \\
1.53\end{array}$ & $\begin{array}{l}\text { 1. } 13 \\
\text { 1. } 98\end{array}$ & 2.61 \\
\hline $\begin{array}{c}\text { Weight } \\
\text { Factor } \\
\text { For H.- } \\
\text { For D- }\end{array}$ & & $\begin{array}{r}1.07 \\
.64\end{array}$ & $\begin{array}{r}1.27 \\
.46\end{array}$ & $\begin{array}{r}1.26 \\
.46\end{array}$ & $\begin{array}{r}1.50 \\
.50\end{array}$ & $\begin{array}{r}1.79 \\
.61\end{array}$ & $\begin{array}{r}2.17 \\
.76\end{array}$ & $(.63)$ \\
\hline
\end{tabular}

Table 5 gives the observed $\mathrm{H}^{+}$and $\mathrm{D}^{+}$ions and weighting factors for $\mathrm{H}^{+}$and $\mathrm{D}^{+}$. A small but rather uncertain correction for $\mathrm{H}_{2}^{+}$has been made to the mass 2 peaks of table 2 . The weighting factor is computed from the observed value divided by $\mathrm{H}^{+}+\mathrm{D}^{+}$) times the apriori probability. In $\mathrm{C}_{2} \mathrm{D}_{6}$ it is simply the ratio of $\mathrm{D}^{+}$of $\mathrm{C}_{2} \mathrm{D}_{6}$ to $\mathrm{H}^{+}$of $\mathrm{C}_{2} \mathrm{H}_{6}$. There is a progressive increase in the weighting factor for $\mathrm{H}^{+}$as the number of $\mathrm{D}$ atoms in the atom increases. The factors for $\mathrm{D}^{+}$do not change progressively.

Table 2 includes some small half integer peaks that come from doubly charged ions of mass 27, 29, 31, and 33. Doubly charged ions of even mass number are masked by singly charged ions. The more abundant ions contain 4 and 5 hydrogenic atoms. In the case of $\mathrm{C}_{2} \mathrm{HD}_{5}$ the relative abundance of the pairs of ions containing 4 or 5 hydrogenic atoms can be computed if it is assumed that the same weighting factors apply in doubly and singly charged ions. Peak 15.5 of abundance 0.57 comes from $\mathrm{C}_{2} \mathrm{HD}_{3}{ }^{++}$and from table $3, \mathrm{C}_{2} \mathrm{D}_{4}{ }^{++}$will have an abundance of about 0.39 . The abundance of the pair is 0.96 . The 16.5 peak of abundance 0.24 is $\mathrm{C}_{2} \mathrm{HD}_{4}{ }^{++} . \quad \mathrm{C}_{2} \mathrm{D}_{5}{ }^{++}$is about 0.09 and the abundance of the pair of ions with 5 hydrogenic ions is 0.33 . The abundance of $\mathrm{C}_{2} \mathrm{H}_{5}{ }^{++}$of $\mathrm{C}_{2} \mathrm{H}_{6}$ is 0.54 .

The doubly charged ions of $\mathrm{C}_{2} \mathrm{HD}_{5}$ make contributions of about 0.39 to the 16 peak and 0.09 to the 17 peak on the basis of the above assumptions. There is no good basis for computing contributions of doubly charged ions to the 14, 15, 16, and 17 peaks of other deuteroethanes but they are a source of experimental uncertainty in the data of table 4 . In the case of $\mathrm{C}_{2} \mathrm{H}_{6}$ the abundance of $\mathrm{C}_{2} \mathrm{H}_{4}{ }^{++}$will be approximately like that of the pair of ions from $\mathrm{C}_{2} \mathrm{HD}_{5}$ of abundance 0.96 .

(Paper 65A2-89)

\section{Summary}

The mass spectra of deuteroethylenes [6] and deuteromethanes [5] show a regular trend in the probability of removing $\mathrm{H}$ and $\mathrm{D}$ atoms from molecules with increasing numbers of $\mathrm{D}$ atoms in the molecule. In the $\mathrm{C}_{2}$ range there is no appreciable difference between the patterns of symmetrical and unsymmetrical dideuteroethylenes. In these molecules it is logical to compute "weighting factors" on the basis of the $\mathrm{C}_{2} \mathrm{H}_{4}$ or $\mathrm{CH}_{4}$ spectra. In the case of the ethanes there is no regular trend. There are large differences in the relative abundance of molecule ions and there are striking differences between symmetrical and unsymmetrical molecules. Only in the case of the $\mathrm{C}_{2} \mathrm{HD}_{5}$ pattern is there a logical basis for computing weighting factors for removing $\mathrm{H}$ and $\mathrm{D}$.

It is consistent with the statistical theory of mass spectra of polyatomic molecules [7] that there will be some differences in patterns of deuteroethanes because of differences in vibration levels of $\mathrm{D}$ and $H$ atoms. This is a complicated problem and beyond the scope of this paper.

It will be of interest to obtain the patterns of the other deuteroethanes, $\mathrm{CH}_{2} \mathrm{D} \cdot \mathrm{CHD}_{2}$ and $\mathrm{CH}_{2} \mathrm{D} \cdot \mathrm{CD}_{3}$ for these undoubtedly differ from the isomers available for this study. This is needed for analytical purposes. For instance there is a small uncertainty in this work because $\mathrm{C}_{2} \mathrm{H}_{2} \mathrm{D}_{4}$ is the most abundant impurity in $\mathrm{C}_{2} \mathrm{HD}_{5}$ and $\mathrm{C}_{2} \mathrm{H}_{3} \mathrm{D}_{3}$ is the most abundant in $\mathrm{CHD}_{2} \cdot \mathrm{CHD}_{2}$. We used the patterns of $\mathrm{CHD}_{2}$. $\mathrm{CHD}_{2}$ and $\mathrm{CH}_{3} \mathrm{CD}_{3}$ for the corrections but it would be better to use the mean patterns of the two isomers if both were known.

The experimental material in this paper was used by Miss Quinn as a Master's thesis at the University of Alabama.

\section{References}

[1] Schissler, Thompson and Turkevich, Farad. Soc. Discussion 10 (1951).

[2] V. H. Dibeler, J. Res. NBS 44, 489 (1950) RP2095.

[3] D. P. Stevenson and C. D. Wagner, J. Chem. Soc. 72, $5612(1952)$.

4] F. H. Field and J. L. Franklin, Electron Impact Phenomena (Academic Press, New York, N.Y., 1957).

[5] Mohler, Dibeler, and Quinn, J. Research NBS 61, 171 (1958) RP2896.

[6] Dibeler, Mohler, and deHemptinne, J. Research NBS 53, 107 (1954) RP2522

[7] Rosenstock, Wallenstein, Wahrhaftig, and Eyring, Proc. Nat. Acad. Sci. 38, 667 (1952). 